\title{
Effect of rapid warming of bull and rabbit semen
}

\author{
K. Bamba and D. G. Cran* \\ Faculty of Agriculture, Shizuoka University, Shizuoka, Japan and *AFRC Institute of Animal \\ Physiology and Genetics Research, Babraham, Cambridge CB2 4AT, U.K.
}

\begin{abstract}
Summary. Rapid warming of semen from 5 to $37^{\circ} \mathrm{C}$ caused visible damage to the acrosomes of bull and rabbit spermatozoa. The degree and type of damage varied with the species, the bull being the more resistant. While vesiculation was observed in rabbit spermatozoa, neither warm nor cold shock resulted in this defect in the bull. Warm shock of bull spermatozoa caused acrosomal knobbing in an anterior region of the head. Spermatozoa with thread and/or droplet-like structures were frequently observed in bull semen after cold shock.
\end{abstract}

Keywords: bull; rabbit; rapid warming; spermatozoa; morphology

\section{Introduction}

It has been shown that rapid dilution of chilled $\left(5^{\circ} \mathrm{C}\right)$ boar semen with a warm diluent $\left(37^{\circ} \mathrm{C}\right)$ exerts a deleterious effect on acrosomal morphology which is likely to be mainly due to the warming component (Bamba \& Cran, 1985). This finding has indicated the possibility that warm shock occurs during rapid thawing of frozen semen. Indeed, sperm damage due to post-thaw warming of cold semen has been reported for the bull (Senger et al., 1976; De Abreu et al., 1979). However, little is known about nature of warm shock in spermatozoa of domestic animals other than the boar. The examination of this phenomenon in different species may provide useful information for understanding the mechanism of cold shock and also for establishing more effective procedures for freezing semen.

The present study was therefore performed to examine the nature of rapid warming using bull and rabbit spermatozoa.

\section{Materials and Methods}

Bull and rabbit semen were collected using an artificial vagina.

Preparation of spermatozoa. Bull semen was diluted 1:4 (v/v) with BF5 diluent (Pursel \& Johnson, 1975; $1.2 \mathrm{~g} \mathrm{~N}$ Tris-(hydroxymethyl)methyl-2-aminomethane sulphonic acid, $0 \cdot 2 \mathrm{~g}$ Tris(hydroxymethyl)aminomethane, $3 \cdot 2 \mathrm{~g}$ glucose, $0.5 \mathrm{ml}$ Orvus Es Paste (Procter and Gamble, Cincinnati, Ohio) and $20 \mathrm{ml}$ egg yolk per $100 \mathrm{ml}$ ) at $37^{\circ} \mathrm{Cimmediately} \mathrm{after}$ collection, and subsequently cooled to $5^{\circ} \mathrm{C}$ over a 3-h period. Rabbit ejaculates with good initial motility were pooled and diluted $1: 3(\mathrm{v} / \mathrm{v})$ with $\mathrm{BF} 5$ diluent at room temperature $\left(20-25^{\circ} \mathrm{C}\right)$. The interval from semen collection to dilution was not more than $1 \mathrm{~h}$. Diluted semen was cooled to $5^{\circ} \mathrm{C}$ over a 2 -h period.

The cooled diluted semen samples were subjected to rapid dilution treatments immediately or after gradual warming to $37^{\circ} \mathrm{C}$.

Experimental treatments. Semen samples $(0.2 \mathrm{ml})$ at 5 and $37^{\circ} \mathrm{C}$ were pipetted rapidly into $1.6 \mathrm{ml}$ BTS medium (Pursel \& Johnson, 1975; $3.7 \mathrm{~g}$ glucose, $0.6 \mathrm{~g}$ trisodium citrate dihydrate, $0.125 \mathrm{~g} \mathrm{NaHCO}_{3}, 0.125 \mathrm{~g}$ disodium EDTA and $0.075 \mathrm{~g} \mathrm{KCl}$ per $100 \mathrm{ml}$ ) at $5^{\circ} \mathrm{C}$ (rapid dilution at $5^{\circ} \mathrm{C}$ and rapid cooling treatment) and at $37^{\circ} \mathrm{C}$ (rapid warming and rapid dilution at $37^{\circ} \mathrm{C}$ treatment). The samples diluted at $5^{\circ} \mathrm{C}$ were equilibrated at this temperature for 2 min and then gradually warmed to $37^{\circ} \mathrm{C}$.

Evaluation of spermatozoa. Motility and acrosomal evaluations were made on samples equilibrated at $37^{\circ} \mathrm{C}$ for at least 5 min. Motility was estimated as described by Bamba \& Cran (1985), and was expressed as the percentage of 

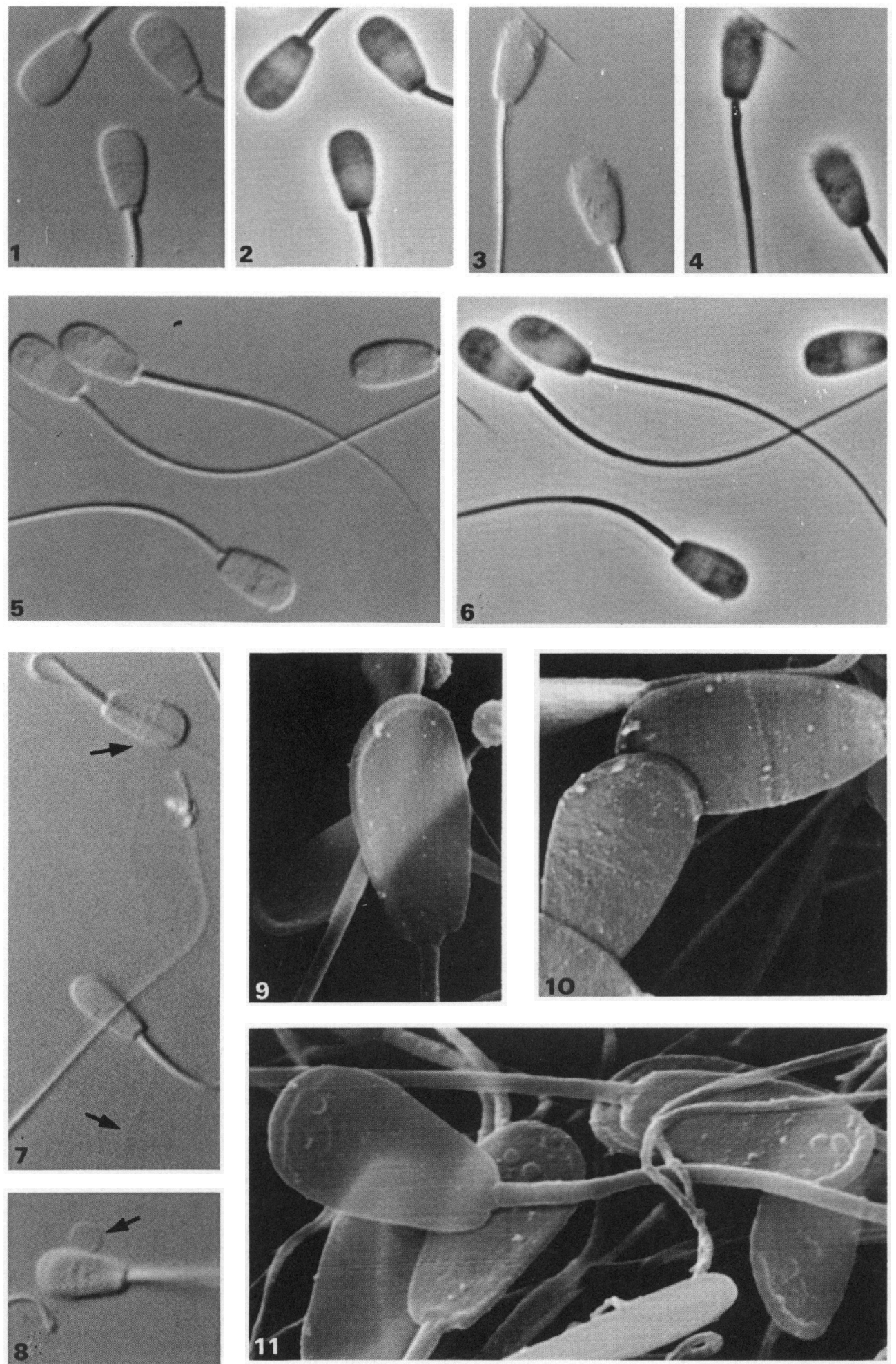
progressively motile spermatozoa. In the bull the majority of motile spermatozoa had bent tails after rapid cooling and swam backwards. These actively motile cells were included in the motility percentage.

Samples for acrosomal evaluation were diluted $1: 1(\mathrm{v} / \mathrm{v})$ with formol-BTS (BTS containing $0 \cdot 4 \%$ formaldehyde) at the same temperature and then examined with phase-contrast or differential interference-contrast microscopy at $\times 750$ magnification. Spermatozoa with a crescent-shaped apical ridge were regarded as having a normal acrosome. Bull spermatozoa with wrinklings or dark areas on the anterior region of the acrosome were regarded as abnormal (Figs $5 \&$ 6). At least 200 spermatozoa were examined for each treatment, and samples for transmission and scanning electron microscopy were processed as described by Bamba \& Cran (1985).

Statistical analysis. Data were subjected to analysis of variance and the difference between treatment means were tested by Tukey's procedure (Steel \& Torrie, 1960).

Bull

\section{Results}

While there was variation between animals, it was clear that rapid warming caused a significant drop in the proportion of normal acrosomes without affecting the motility of the cells (Table 1). In

Table 1. Effect of rapid dilution and temperature change on motility and acrosomal morphology of bull spermatoza

\begin{tabular}{lrrlll}
\hline & \multicolumn{5}{c}{ Motility (normal acrosome) \% } \\
\cline { 2 - 6 } Treatment & Bull 1 & Bull 2 & Bull 3 & Total \\
\hline Control $\left(5^{\circ} \mathrm{C}\right)$ & $83(93)$ & $85(98)$ & $85(94)$ & $84 \cdot 1$ & $(94 \cdot 8 \pm 2 \cdot 9)$ \\
Rapid dilution at $5^{\circ} \mathrm{C}$ & $78(91)$ & $78(96)$ & $85(90)$ & $80 \cdot 0$ & $(92 \cdot 3 \pm 3 \cdot 4)$ \\
Rapid warming & $78(5)$ & $78(65)$ & $85(26)$ & $80 \cdot 0$ & $(31 \cdot 7 \pm 27 \cdot 6)^{*}$ \\
Rapid dilution at $37^{\circ} \mathrm{C}$ & $78(90)$ & $80(94)$ & $85(91)$ & $80 \cdot 8$ & $(91 \cdot 5 \pm 3 \cdot 0)$ \\
Rapid cooling & $0(6)$ & $1(2)$ & $23(18)$ & $7 \cdot 6^{*}$ & $(8 \cdot 4 \pm 9 \cdot 8)^{*}$ \\
Slow warming to $37^{\circ} \mathrm{C}$ & $83(92)$ & $85(97)$ & $85(95)$ & $84 \cdot 1$ & $(94 \cdot 5 \pm 2 \cdot 1)$ \\
\hline
\end{tabular}

Values are mean or mean \pm s.d.

Replicate tests were made on 6 ejaculates, two each of 3 bulls.

${ }^{*} P<0.01$ compared with control value.

Figs 1 \& 2. Bull spermatozoa with a normal acrosome. Fig. 1, Nomarski; Fig. 2, phase contrast. $\times 1250$.

Figs $3 \& 4$. Bull spermatozoa after rapid cooling. Some debris of membranes is left on the surface of head (Fig. 3) and the head appearance is fuzzy (Fig. 4). Fig. 3, Nomarski; Fig. 4, phase contrast. $\times 1250$.

Figs 5 \& 6. Bull spermatozoa after rapid warming. Note the wrinklings on the anterior part of head (Fig. 5), which are seen as dark areas by phase-contrast microscopy (Fig. 6). The degree of alteration in the apical ridge varies with spermatozoa. Fig. 5, Nomarski; Fig. 6, phase contrast. $\times 1250$.

Figs 7 \& 8. Bull spermatozoa after rapid cooling. A spermatozoon with a thread-like particle (arrows show both ends), which is as long as the total length of spermatozoon (Fig. 7), and that with droplet-like particle (arrow, Fig. 8). Nomarski. $\times 1250$.

Fig. 9. Bull spermatozoon with a normal acrosome. SEM, $\times 5200$.

Fig. 10. Bull spermatozoa after rapid cooling. Most of the acrosome appears to be removed. The equatorial segment is visible. SEM, $\times 5200$.

Fig. 11. Bull spermatozoa after rapid warming. Note the blister-like structures in the anterior acrosome and the ruffling of the apical ridge. SEM, $\times 5200$. 

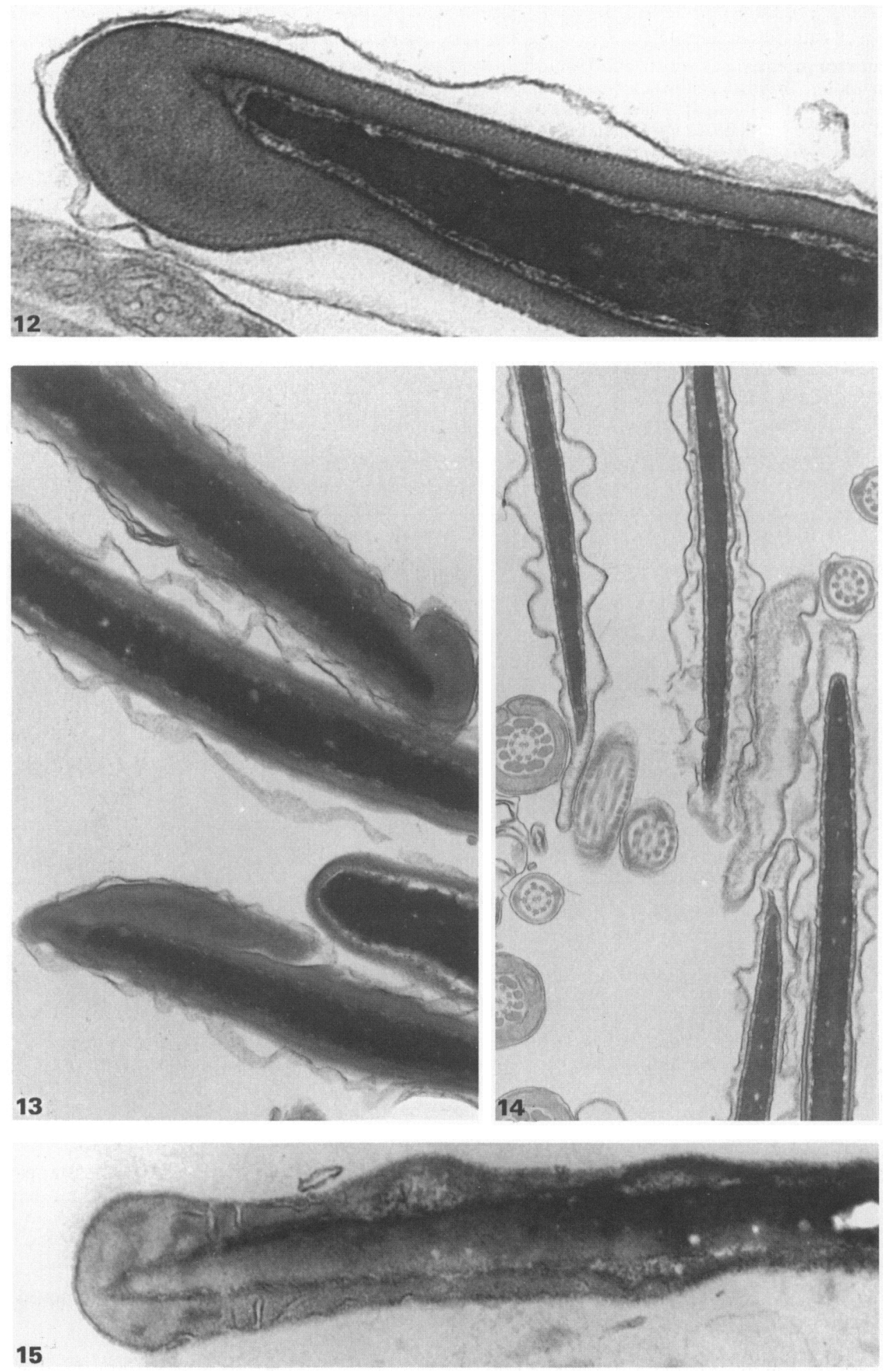
contrast, gradual warming had no such detrimental effect nor was there a significant change following rapid dilution at 5 or $37^{\circ} \mathrm{C}$. Rapid cooling resulted in a major loss in motility and accompanying acrosomal integrity.

Both rapid warming (Figs 5, 6,11 \& 13) and rapid cooling of spermatozoa (Figs 3, 4, 10 \& 14) resulted in structural changes which distinguished them from those with normal acrosomes (Figs 1 , $2,9 \& 12$ ). Control spermatozoa at $5^{\circ} \mathrm{C}$ had crescent-shaped apical ridges (Figs 1, 2 \& 9) with a smooth surface (Figs $1 \& 9$ ) and sagittal sections of normal spermatozoa showed a distinct apical ridge (Fig. 12). After rapid cooling the surface of the sperm head became rough (Figs $3 \& 10$ ) and had a fuzzy appearance (Fig. 4). Following overnight storage of rapidly cooled spermatozoa in fixative ( $1 \%$ glutaraldehyde, $0.4 \%$ formaldehyde) it was often observed that the cells bore threadlike (Fig. 7) or droplet-like structures (Fig. 8). With scanning electron microscopy it was apparent that much of the surface membranes had been removed (Fig. 10), while with the transmission electron microscope it was clear that there had been a loss of acrosomal contents together with the classical disruption of the plasma membrane (Fig. 14). On the anterior surface of the head, rapid warming caused wrinklings (Fig. 5) which were seen as dark areas with phase-contrast microscopy (Fig. 6). This type of change was observed in most of the spermatozoa categorized as having abnormal acrosomes. The degree of alteration of the apical ridge, on the other hand, varied between spermatozoa (Fig. 5). With scanning electron microscopy it was observed that the spermatozoa had a characteristic appearance after rapid warming with a ruffled apical ridge and blister-like structures on the anterior region of the acrosome (Fig. 11). In thin section (Fig. 13) it was seen that the apical ridge recurved over the acrosomal surface to form a ' $k$ nob' and that the outer acrosomal membrane was ruffled.

\section{Rabbit}

In the rabbit, rapid warming induced quantitative acrosomal changes similar to those observed for the bull. As for the bull, this treatment did not affect the motility of the spermatozoa (Table 2). Unlike the bull, however, rabbit spermatozoa did not undergo 'knobbing', but formed marked invaginations of the outer acrosomal membrane into acrosomal matrix in a manner similar to that observed for the boar (Fig. 15).

\section{Discussion}

The results of present study showed that rapid dilution and warming treatment caused visible acrosomal damage in bull and rabbit spermatozoa, whereas the stress did not affect motility. These results agree with those obtained for the boar (Bamba \& Cran, 1985). Since rapid dilution per se had little influence in these spermatozoa, warming would be a main factor affecting acrosomes. However, the effect of dilution might be mediated through an interaction with warming, presumably through increasing the rate of warming.

Fig. 12. Sagittal section of a bull spermatozoon with a normal acrosome. TEM, $\times 54000$.

Fig. 13. Bull spermatozoa after rapid warming. Note the deformation of the apical ridge which resembles the defect known as 'knobbing'. TEM, $\times 24000$.

Fig. 14. Bull spermatozoa after rapid cooling. Note the classical disruption of plasma membrane and loss of acrosomal content. TEM, $\times 17400$.

Fig. 15. Rabbit spermatozoon after rapid warming. Note the marked invagination of outer acrosomal membrane. TEM, $\times 27150$. 
So far as the susceptibility of acrosomes to warm shock is concerned, this differs between species and between individual males; bull spermatozoa are the most resistant and those of the boar the most susceptible, and the variation between males is greater in the bull than in the boar.

Morphological studies on warm-shocked spermatozoa demonstrated that acrosomal alterations also varied with the species. When bull and boar spermatozoa are compared, the differences in the morphological changes due to rapid warming were quite evident at both light and electron microscopic levels. In bull spermatozoa, rapid warming caused wrinkling in the anterior part of the acrosome which showed blister-like structures in the scanning electron microscope. However, no visible alterations which could correspond to these were seen by transmission electron microscopy. The roughening of the surface was restricted to the anterior acrosome, which may be due to the difference in membrane fluidity between the acrosomal and post-acrosomal regions (Holt \& North, 1984). In some spermatozoa with a roughened surface the apical ridge appeared to be unaltered as viewed with phase-contrast microscopy. However, scanning microscopy showed that most of the cells with blisters had apical ridges which had undergone some change. Further, warm-shocked bull spermatozoa showed a deformation of the apical ridge to give an appearance which superficially resembled the defect known as 'knobbing'.

Table 2. Effect of rapid dilution and temperature change on motility and acrosomal morphology of rabbit spermatozoa

\begin{tabular}{lcccc}
\hline & \multicolumn{4}{c}{ Motility (normal acrosome) \% } \\
\cline { 2 - 5 } Treatment & Replicate 1 & Replicate 2 & Replicate 3 & Total \\
\hline Rapid dilution at $5^{\circ} \mathrm{C}$ & $80(81)$ & $85(90)$ & $50(89)$ & $71 \cdot 6(86 \cdot 6 \pm 4 \cdot 9)^{*}$ \\
Rapid warming & $80(17)$ & $85(34)$ & $50(28)$ & $71 \cdot 6(26 \cdot 3 \pm 8 \cdot 6)$ \\
\hline
\end{tabular}

Values $(\%)$ are mean or mean \pm s.d.

Each replicate composed of 6,9 and 11 pooled ejaculates respectively.

${ }^{*} P<0.01$ compared with rapidly warmed semen.

Aalseth \& Saacke (1985) have reported that motile bull spermatozoa showed pronounced swelling of the apical ridge after being stored in seminal plasma for 5 days at $5^{\circ} \mathrm{C}$. The appearance of these spermatozoa also resembles that of warm-shocked spermatozoa. These structural changes due to warm shock are considered sufficient to account for the impairment of fertility.

After rapid cooling, spermatozoa with thread and/or droplet-like structures were frequently observed in the bull. Although the nature of these structures has not been identified it seems most likely that they result from the emission of acrosomal material through punctate ruptures in the surrounding membranes with their precise shape being determined by the size of the breaks in the membranes.

On the other hand, the majority of motile bull spermatozoa had a bent tail after rapid cooling, and they swam backwards. A similar phenomenon has been noted when high concentrations of glycerol are used in bull sperm diluent (Phillips \& Kalay, 1984). The formation of a bent tail also occurs when mammalian spermatozoa are suspended in hypotonic media (Drevius, 1975). It has been thought that the swelling of the plasma membrane around the tail results in bending or coiling by exerting pressure on the axial fibre and outer sheath (Jones, 1975). According to Cooper (1986), the form that rat spermatozoa assume when swelling in hypotonic media depends partly on the stiffness of the flagellum. In thermal-shocked spermatozoa, the degree of swelling of the plasma membrane and the stiffness of the flagellum may affect the formation of tail bending. Since the plasma membrane was not altered appreciably by warm shock, the stress would not contribute to the formation of a bending tail.

In the boar and bull, no direct relationship appears to exist between the sensitivities to cold and warm shock. This discrepancy suggests that there is a fundamental difference between the effect of cold and warm shock on spermatozoa. Furthermore, the sensitivity to these stresses is clearly 
greater in the outer acrosomal membrane than in the plasma membrane. The components of sperm membranes, particularly the lipid constituents, have been shown to be related to susceptibility of the cells to cold shock (Watson, 1981; Watson \& Plummer, 1985). Darin-Bennett \& White (1977) showed that the susceptibility was correlated with the ratio of cholesterol:phospholipid in spermatozoa; the ratio is thought to be an important determinant of membrane fluidity (Pringle \& Chapman, 1981). In boar spermatozoa, an antioxidant, butylated hydroxytoluene (BHT), showed protective effect against both cold and warm shock (K. Bamba \& D. G. Cran, unpublished observations). The action of BHT is attributed to its increasing membrane fluidity (Hammerstedt et al., 1976). The fluidity of membranes therefore might play an important role for the determination of sperm sensitivity to thermal shocks. However, a full understanding of these shocks would require further studies using isolated membranes.

Good motility is a necessary prerequisite for fertilization and this parameter is not affected by warm shock. By contrast, the altered morphology of the acrosome would suggest that after warm shock some aspects of fertilizing ability are altered. In a preliminary study, the fertilizing ability of rabbit spermatozoa after warm shock has been tested (K. Bamba \& C. E. Adams, unpublished observations): $78.9 \%(15 / 19)$ of eggs were fertilized in the rabbits inseminated with semen at $5^{\circ} \mathrm{C}$ (motility $75 \%$; normal acrosomes $87 \%$ ) while only $5.2 \%(1 / 19)$ were fertilized in those inseminated with rapidly diluted and warmed semen (motility $75 \%$; normal acrosomes $3 \%$ ), indicating a clear effect of warm shock on fertilizing ability.

Although warm shock is an important factor affecting sperm quality, the advantage of rapid thawing appears to more than compensate for the disadvantage of rapid warming of thawed semen, at least in the bull.

\section{References}

Aalseth, E.P. \& Saacke, R.G. (1985) Morphological change of the acrosome on motile bovine spermatozoa due to storage at $4^{\circ} \mathrm{C}$. J. Reprod. Fert. 74, 473-478.

Bamba, K. \& Cran, D.G. (1985) Effect of rapid warming of boar semen on sperm morphology and physiology. J. Reprod. Fert. 75, 133-138.

Cooper, T.G. (1986) Osmotic swelling of maturing rat spermatozoa and lysis of caput spermatozoa by acylcarnitines and acylcholines. Gamete Res. 14, $47-56$

Darin-Bennett, A. \& White, I.G. (1977) Influence of the cholesterol content of mammalian spermatozoa on susceptibility to cold-shock. Cryobiology 14, 466-470.

De Abreu, R.M., Berndtson, W.E., Smith, R.L. \& Pickett, B.W. (1979) Effect of post-thaw warming on viability of bovine spermatozoa thawed at different rates in French straws. J. Dairy Sci. 62, 1449-1454.

Drevius, L.-O. (1975) Permeability of the bull-sperm membrane. In The Functional Anatomy of the Spermatozoon, pp. 373-383. Ed. B. A. Afzelius. Pergamon Press, Oxford.

Hammerstedt, R.H., Amann, R.P., Rucinsky, T., Morse, P.D., Lepock, J., Snipes, W. \& Keith, A.D. (1976) Use of spin labels and electron spin resonance spectroscopy to characterize membranes of bovine sperm: effect of butylated hydroxytoluene and cold shock. Biol. Reprod. 14, 381-397.

Holt, W.V. \& North, R.D. (1984) Partially irreversible cold-induced lipid phase transitions in mammalian sperm plasma membrane domains: freeze-fracture study. J. exp. Zool. 230, 473-483.

Jones, R.C. (1975) Fertility and infertility in mammals in relation to sperm structure. In The Biology of the Male Gamete, pp. 343-365. Eds J. G. Duckett \& P. A. Racey. Academic Press, London.

Phillips, D.M. \& Kalay, D. (1984) Mechanisms of flagellar motility deduced from backward-swimming bull sperm. J. exp. Zool. 231, 109-116.

Pringle, M.J. \& Chapman, D. (1981) Biomembrane structure and effects of temperature. In Effects of Low Temperatures on Biological Membranes, pp. 21-37. Eds G. J. Morris \& A. Clarke. Academic Press, London.

Pursel, V.G. \& Johnson, L.A. (1975) Freezing of boar spermatozoa: fertilizing capacity with concentrated semen and a new thawing procedure. J. Anim. Sci.40, $99-102$.

Senger, P.L., Becker, W.C. \& Hillers, J.K. (1976) Effect of thawing rate and post-thaw temperature on motility and acrosomal maintenance in bovine semen frozen in plastic straws. J. Anim. Sci. 42, 932-936.

Steel, R.G.D. \& Torrie, J.H. (1960) Principles and Procedures of Statistics. McGraw-Hill Book Co., New York.

Watson, P.F. (1981) The effects of cold shock on sperm cell membranes. In Effects of Low Temperatures on Biological Membranes, pp. 189-218. Eds G. J. Morris \& A. Clarke. Academic Press, London.

Watson, P.F. \& Plummer, J.M. (1985) The responses of boar sperm membranes to cold shock and cooling. Proc. Ist Int. Conf. Deep Freezing of Boar Semen, Uppsala, 113-127.

Received 15 May 1987 